\title{
Estratégias de saúde realizadas por/para mulheres negras nas
}

\author{
Américas: revisão de escopo
}

\section{Health Strategies from / for Black Women in the Americas: scope review}

\author{
Clélia R. S. Prestes ${ }^{2}$ \\ Felipe L. Fachim ${ }^{3}$, \\ Vera S. F. Paiva
}

Submetido em 13 e aprovado em 15 de novembro de 2018.

Resumo: Este artigo apresenta um panorama de estratégias de promoção da saúde de mulheres negras, voltadas à potencialização de resiliência, agência, emancipação, autonomia ou empoderamento. Os dados apresentados neste artigo correspondem a parte dos resultados coletados por uma revisão sistemática de escopo, que integrou a pesquisa Estratégias de promoção da saúde de mulheres negras: interseccionalidade e bem viver, com descrição de experiências reconhecidas no campo científico. Discutimos 11 estratégias estadunidenses e 1 brasileira, apresentando seus objetivos, perspectivas teóricas, descrições, quem as realizou, perfil de participantes, método, técnicas e instrumentos, além de discutir alguns resultados e o panorama geral, em diálogo com as perspectivas teóricas da abordagem multicultural dos direitos humanos na saúde e do feminismo negro. Ao final, apontamos recomendações para agendas futuras, no sentido da atenção à interseccionalidade como método de análise e ação, produções teóricas de diversas regiões, epistemologias e cosmovisões, consideração das demandas específicas, responsabilidade ampla pela saúde das mulheres negras, valorização das experiências das mesmas, incluindo as não-acadêmicas, o feminismo negro como estratégia de enfrentamento das colonialidades de poder, diversidade na formação de equipes e fontes teóricas, ampliação das publicações de pesquisadoras(es) negras(os) e do movimento social negro e de mulheres negras, e ampliação das vozes de autoras(es) amefricanas(os).

Palavras-chave: Mulheres. Relações Raciais. Promoção de Saúde. Psicologia Social (Aspectos Psicossociais). Feminismo negro.

Abstract: This article presents an overview of strategies to promote the health of black
women, aimed at enhancing resilience, agency, emancipation, autonomy or empowerment.
The data presented in this article corresponds to part of the results collected by a systematic
scope review, which integrated the research Strategies to promote the health of black
women: intersectionality and well being, with description of recognized experiences in
the scientific field. We discussed 11 United States and 1 Brazilian strategies, presenting
their objectives, theoretical perspectives, descriptions, who performed them, profile of
participants, method, techniques and instruments, discussed some results and the general
perspectives, in dialogue with the theoretical perspectives of multicultural approach to
human rights in health and black feminism. In the end, we point out recommendations for 
future agendas, focusing attention on intersectionality as a method of analysis and action, theoretical productions of different regions, epistemologies and worldviews, considering specific demands, broad responsibility for the health of black women, valuing their experiences, including the non-academic, black feminism as strategy for confronting the colonialities of power, diversity in the formation of teams and theoretical sources, expansion of the publications from black researchers, from the black people's social movements and from black women in general, and the amplification of the voices of the amefrican authors.

Key words: Women. Racial Relations. Health Promotion. Social Psychology (Psychosocial Aspects). Black feminism.

Quais e como são as estratégias de promoção da saúde de mulheres negras, voltadas à potencialização de resiliência, agência, emancipação, autonomia ou empoderamento? Quais as especificidades e complementaridades entre as experiências reconhecidas no campo científico e as reconhecidas no campo do movimento negro e de mulheres negras? Essas perguntas guiaram a pesquisa ${ }^{5}$ Estratégias de promoção da saúde de mulheres negras: interseccionalidade e bem viver (PRESTES, 2018).

Interessadas em desenvolver uma agenda para formação em abordagens voltadas à saúde que enfrentem a opressão multidimensional que afeta mulheres negras, produzimos um panorama de experiências existentes e reconhecidas, utilizando os procedimentos de descrição e avaliação. Um mesmo roteiro semiestruturado orientou uma revisão da literatura científica, foco deste artigo, e entrevistas com informantes-chave para coleta de experiências reconhecidas no movimento negro e de mulheres negras. Descrevemos a perspectiva teórica e a duração das estratégias, o tipo de intervenção e seus métodos, os(as) participantes, e consideramos o que apontavam como pontos fortes e fracos e as sugestões derivadas para novos trabalhos.

Por fim, avaliamos as especificidades e complementaridades dos conteúdos reconhecidos em ambos os campos, com base em categorias que tratavam dos referenciais e modos de fazer, dos pontos altos e do lugar das mulheres negras. A análise, assim como as definições metodológicas, foi orientada pela abordagem multicultural dos direitos humanos na saúde e pelo feminismo negro. Daí termos utilizado como referências centrais os conceitos de interseccionalidade (como método de análise e de ação) e bem viver (como cosmovisão e horizonte ético-político). 
A revisão sistemática (de escopo) coletou estratégias reconhecidas por pares de diferentes campos científicos, disponíveis em oito bases de dados (ASSIA, BVS, ERIC, LILACS, MEDLINE, Psynet, Sociological Abstracts e Web of Science). Estudos preliminares e pré-testes da busca apuraram a sintaxe definitiva e o modo de fazer a revisão; a leitura e a seleção dos artigos foram, então, devidamente padronizadas, processo registrado e feito de modo pareado.

Na fórmula de busca, utilizamos termos referentes a processos que, potencializados, contribuem para a saúde de mulheres negras e que dialogam com os referenciais teóricos adotados. A sintaxe incluiu, portanto, as palavras-chave resiliência, agência, emancipação, autonomia e empoderamento, associadas aos termos mulheres e raça.

Identificamos 829 artigos, publicados entre janeiro de 2007 e janeiro de 2018. Pela leitura, selecionamos aqueles que descreviam intervenções e que, de fato, contribuíam para a potencialização de pelo menos um dos processos citados. A partir do consenso entre avaliadores, foram incluídos catorze artigos na pesquisa. Desses, doze artigos (referências na tabela 1, ao final deste texto) permitiram-nos apresentar um escopo das estratégias realizadas nas Américas, sendo onze estadunidenses e um artigo brasileiro. Estão publicados em revistas nas áreas de enfermagem, saúde pública, educação em saúde, estudos culturais e feministas, educação e psicologia social; tratam de estratégias de apoio a mulheres negras, da promoção da sua saúde, além de ações conjuntas dedicadas à cidadania e à emancipação.

Na tabela 2, apresentamos alguns conteúdos dos artigos, ou seja, seus objetivos, perspectiva teórica, descrição, realização, perfil de participantes, métodos, técnicas e instrumentos utilizados. 
Tabela 2 - Objetivos, perspectiva teórica, descrição, realização, participantes, métodos, técnicas e instrumentos dos artigos

\begin{tabular}{|c|c|c|c|c|c|}
\hline Artigo & Objetivos & Perspectiva teórica & Descrição e Realização & Participantes & $\begin{array}{l}\text { Métodos, técnicas e } \\
\text { instrumentos }\end{array}$ \\
\hline $\begin{array}{c}1 \\
\text { Andrews e cols. }\end{array}$ & $\begin{array}{c}\text { Testar a efetividade da } \\
\text { intervenção para parar } \\
\text { de fumar "Sister to } \\
\text { Sister", } \\
\text { de tipo comunitária } \\
\text { entre pares entre } \\
\text { mulheres afro- } \\
\text { americanas vivendo } \\
\text { em projetos de } \\
\text { desenvolvimento } \\
\text { habitacional e } \\
\text { em casas subsidiadas. } \\
\text { As Trabalhadoras } \\
\text { Comunitárias em Saúde } \\
\text { foram previamente } \\
\text { capacitadas. }\end{array}$ & $\begin{array}{c}\text { Perspectiva } \\
\text { sociocognitiva de } \\
\text { aconselhamento- } \\
\text { comportamental: apoio } \\
\text { social e estímulo de } \\
\text { auto-eficácia ("você } \\
\text { pode fazer!). } \\
\text { Adaptada da PHS } \\
\text { Treating tobacco } \\
\text { dependence guideline } \\
\text { associado a ações de } \\
\text { empoderamento cuja } \\
\text { referência (citada) é } \\
\text { Paulo Freire. } \\
\text { O investimento no bem- } \\
\text { estar é também espiritual } \\
\text { que é definido em termos } \\
\text { de "Estados cognitivos" }\end{array}$ & $\begin{array}{c}\text { Três componentes de um modelo } \\
\text { "colaborativo-participatório" } \\
\text { a. } 6 \text { semanas com sessões de } \\
\text { aconselhamento-comportamental } \\
\text { e de empoderamento em grupo, } \\
\text { com "booster" na 12a e na 24a } \\
\text { semana. } \\
\text { b. terapia de substituição da } \\
\text { nicotina; } \\
\text { c. contato pessoal semanal } \\
\text { com trabalhador comunitário } \\
\text { da saúde (TCS) para favorecer } \\
\text { a auto-eficácia em parar de } \\
\text { fumar, oferecendo apoio social } \\
\text { e para o bem-estar espiritual, } \\
\text { compartilhando trechos bíblicos, } \\
\text { orações, poemas e meditações } \\
\text { que inspiram. As TCS deveriam } \\
\text { usar a linguagem e cultura } \\
\text { local. A intervenção está bem } \\
\text { detalhada. Realizada por } \\
\text { pesquisadores acadêmicas da } \\
\text { enfermagem e a trabalhadora } \\
\text { comunitária da saúde (TCS) era } \\
\text { uma mulher negra, ex-fumante e } \\
\text { nativa na comunidade. }\end{array}$ & $\begin{array}{l}\text { Mulheres afro-americanas } \\
\text { maiores de } 18 \text { anos } \\
\text { que fumam todos os } \\
\text { dias e planejam parar } \\
\text { de fumar em } 6 \text { meses, } \\
\text { residentes na comunidade } \\
\text { de intervenção ou na } \\
\text { comunidade posta em } \\
\text { comparação, ou suas } \\
\text { amigas ou parentes. } \\
\text { Foram excluídas as com } \\
\text { diagnóstico de distúrbio } \\
\text { psíquico ou quadro de } \\
\text { angina instável / infarto } \\
\text { do miocárdio recente, } \\
\text { assim como as que apenas } \\
\text { começam a considerar } \\
\text { parar de fumar. }\end{array}$ & $\begin{array}{c}\text { Desenho quase- } \\
\text { experimental, utilizou } \\
\text { medidas repetidas com } \\
\text { grupo de comparação. } \\
\text { Os dados foram } \\
\text { coletados dos grupos } \\
\text { de intervenção e de } \\
\text { comparação na semana } \\
\text { de linha de base, na } 6^{\text {a }} \\
\text { semana, na } 12^{\mathrm{a}} \text { semana } \\
\text { e na } 24^{\mathrm{a}} \text { semana. A } \\
\text { abstinência do uso } \\
\text { do cigarro foi medida } \\
\text { através do auto-relato } \\
\text { e validada através } \\
\text { dos Instrumentos } \\
\text { Bedfont (2002) } \\
\text { EC50-Smokerlyzer } \\
\text { (Innovative Marketing, } \\
\text { Medford, NJ). }\end{array}$ \\
\hline
\end{tabular}


(continuação)

\begin{tabular}{|c|c|c|c|c|c|}
\hline Artigo & Objetivos & Perspectiva teórica & Descrição e Realização & Participantes & Métodos, técnicas e instrumentos \\
\hline $\begin{array}{c}2 \\
\text { Bair }\end{array}$ & $\begin{array}{l}\text { Descrever as teorias de } \\
\text { Nannie Helen Burroughs } \\
\text { (1883-1961), fundadora } \\
\text { da National Training } \\
\text { School for Women and } \\
\text { Girls em } 1909 \text { e discutir } \\
\text { o currículo da Educação } \\
\text { Social na Escola }\end{array}$ & $\begin{array}{l}\text { Educação Social na } \\
\text { Escola }\end{array}$ & $\begin{array}{c}\text { Criação de Rede Nacional que incluiu o } \\
\text { ensino de história negra e o tema da não } \\
\text { segregação, além de uma educação para a } \\
\text { prática ("pratical education") na Escola de } \\
\text { Capacitação para Mulheres e Meninas. } \\
\text { (Training School for Women and Girls) } \\
\text { Realizada por Nannie Helen Burroughs } \\
(1883-1961)\end{array}$ & $\begin{array}{l}\text { Mulheres jovens e } \\
\text { negras do começo do } \\
\text { séc XX. }\end{array}$ & $\begin{array}{l}\text { A pesquisa descreve o currículo } \\
\text { de estudos sociais e práticas } \\
\text { pedagógicas da educação social } \\
\text { ("ensinar e aprender como indivíduos } \\
\text { constroem e vivenciam as relações } \\
\text { sociais, políticas e econômicas-- } \\
\text { no passado e no presente-e as } \\
\text { implicações em como os cidadãos } \\
\text { são educados em uma democracia”. }\end{array}$ \\
\hline $\begin{array}{c}3 \\
\text { Barlow }\end{array}$ & $\begin{array}{l}\text { Construir um espaço } \\
\text { onde mulheres negras } \\
\text { possam encontrar alívio } \\
\text { a partir de momentos de } \\
\text { lucidez e inteligibilidade } \\
\text { falando sobre amor } \\
\text { próprio, autocuidado, } \\
\text { saúde mental e bem-estar. }\end{array}$ & $\begin{array}{c}\text { Perspectiva } \\
\text { comunitária que } \\
\text { utiliza o conceito } \\
\text { de "discourse on } \\
\text { the gaze" de bell } \\
\text { hooks, no campo do } \\
\text { feminismo negro: o } \\
\text { olhar que alimenta } \\
\text { estereótipos e reforça } \\
\text { políticas baseadas } \\
\text { nesses estereótipos } \\
\text { sobre mulheres } \\
\text { negras. }\end{array}$ & $\begin{array}{c}\text { Educação de e por pares com troca de } \\
\text { experiências e histórias pessoais sobre } \\
\text { amor e saúde mental. Usam meio digital } \\
\text { e os arquivos no site SOS - Saving our } \\
\text { Sisters. } \\
\text { Desenvolver o reconhecimento dos } \\
\text { estressores cotidianos e a resistência } \\
\text { ao olhar estereotipado (desvalorizado, } \\
\text { desumanizado, objetificado) para adotar } \\
\text { um olhar de resistência e de oposição para } \\
\text { "construirmo-nos como sujeitos da nossa } \\
\text { vida cotidiana". } \\
\text { Os depoimentos resultantes de perguntas } \\
\text { do grupo focal foram incluídos na website } \\
\text { que serviu de espaço de disseminação para } \\
\text { essas narrativas. As histórias sobre saúde } \\
\text { mental e bem-estar fazem parte de uma } \\
\text { ampla campanha de mídia onde mulheres } \\
\text { negras são o centro. } \\
\text { Realizada por psicólogas comunitárias e } \\
\text { outras agentes de saúde com experiência } \\
\text { em estudos de gênero }\end{array}$ & Mulheres negras & $\begin{array}{l}\text { Ensaio crítico descritivo da } \\
\text { experiência de produzir as narrativas } \\
\text { digitais e pessoais de mulheres } \\
\text { negras, produzidas inicialmente } \\
\text { em } 5 \text { grupos focais, acompanhado } \\
\text { de plano de aulas que permite } \\
\text { professoras determinar como } \\
\text { desenvolver estratégias nessa mesma } \\
\text { direção. } \\
\text { As perguntas respondidas foram: } \\
\text { 1. Quando você se apaixonou por } \\
\text { você mesma? 2. O que significa } \\
\text { felicidade para você? 3. Como a } \\
\text { sua experiência como mulher negra } \\
\text { afeta sua saúde, especificamente sua } \\
\text { saúde mental e bem-estar? } 4 \text {. Como } \\
\text { você pode se respeitar hoje, e todos } \\
\text { os dias? Gravados em áudio-tape e } \\
\text { vídeo digital. }\end{array}$ \\
\hline
\end{tabular}

(continua) 
(continuação)

\begin{tabular}{|c|c|c|c|c|c|}
\hline Artigo & Objetivos & Perspectiva teórica & Descrição e Realização & Participantes & $\begin{array}{l}\text { Métodos, técnicas e } \\
\text { instrumentos }\end{array}$ \\
\hline $\begin{array}{c}4 \\
\text { Cooper } \\
\text { e cols. }\end{array}$ & $\begin{array}{l}\text { Determinar a } \\
\text { efetividade de } \\
\text { programa TEACH } \\
\text { - Transforming, } \\
\text { Empowering, } \\
\text { and Affecting } \\
\text { Congregation } \\
\text { Health de nutrição } \\
\text { e exercício baseada } \\
\text { na Faith Community } \\
\text { Nursing: Scope and } \\
\text { Standards of Practice } \\
\text { e na noção de } \\
\text { competência cultural. } \\
\text { O projeto } \\
\text { presume que as } \\
\text { as comunidades } \\
\text { religiosas são } \\
\text { atravessadas por } \\
\text { desigualdades, } \\
\text { inclusive na } \\
\text { experiência de saúde. }\end{array}$ & $\begin{array}{c}\text { Oficinas baseadas } \\
\text { no programa Eat } \\
\text { Healthy Be Active } \\
\text { (ODPHP,2014) } \\
\text { ChooseMyPlate. } \\
\text { gov e no Presidential } \\
\text { Active Lifestyle Award } \\
\text { Program entre outros } \\
\text { do Departamento } \\
\text { Federal de Agricultura, } \\
\text { de perspectiva } \\
\text { sociocognitiva e que } \\
\text { integra "promoção } \\
\text { da saúde baseada } \\
\text { na comunidade de } \\
\text { fé (em torno das } \\
\text { Igrejas), considerando } \\
\text { necessidades } \\
\text { individuais e espirituais }\end{array}$ & $\begin{array}{l}\text { Detalhada intervenção de } \\
\text { "intervenção para a saúde } \\
\text { culturalmente adaptada" que } \\
\text { consiste de encontros } 2 \text { vezes } \\
\text { por semana por } 1 \text { hora com } \\
\text { mulheres negras significadas } \\
\text { como "população alvo": } \\
\text { 1o encontro para exercícios } \\
\text { (dança Africana, de salão e } \\
\text { ou swing dance, ou yoga, } \\
\text { ou cardio e aeróbicos). São } \\
\text { encorajadas a fazer mais } 90 \\
\text { minutos de exercício em casa. } \\
\text { 2o encontro capacitação } \\
\text { para mudar estilo de vida e } \\
\text { aprender cardápios a baixo } \\
\text { custo e saudáveis. } \\
\text { Realizada por enfermeiras de } \\
\text { saúde pública na comunidade } \\
\text { e educadores em saúde, além } \\
\text { de voluntários na comunidade } \\
\text { religiosa }\end{array}$ & $\begin{array}{l}\text { Mulheres negras obesas } \\
\text { e frequentadoras de uma } \\
\text { comunidade religiosa }\end{array}$ & $\begin{array}{l}\text { Medidas colhidas } \\
\text { antes e depois da } \\
\text { intervenção: } \\
\text { Pesagem, medidas } \\
\text { de circunferência } \\
\text { (do pescoço, cintura, } \\
\text { quadril), peso e massa } \\
\text { corporal. } \\
\text { Preocupa-se com } \\
\text { indicadores de } \\
\text { "sustentabilidade" do } \\
\text { projeto, o que é raro } \\
\text { nessa perspectiva. }\end{array}$ \\
\hline
\end{tabular}


(continuação)

\begin{tabular}{|c|c|c|c|c|c|}
\hline Artigo & Objetivos & Perspectiva teórica & Descrição e Realização & Participantes & $\begin{array}{l}\text { Métodos, técnicas e } \\
\text { instrumentos }\end{array}$ \\
\hline $\begin{array}{c}5 \\
\text { De } \\
\text { Marco } \\
\text { e cols. }\end{array}$ & $\begin{array}{l}\text { Descrever a história } \\
\text { de dez anos de } \\
\text { projeto cujo desafio } \\
\text { é ser sensível a } \\
\text { abordagem de gênero, } \\
\text { ser culturalmente } \\
\text { relevante e } \\
\text { conveniente. uiar } \\
\text { uma pesquisa- } \\
\text { participatória de base } \\
\text { comunitária com } \\
\text { pessoas de baixa } \\
\text { renda. }\end{array}$ & $\begin{array}{c}\text { A "Teoria do } \\
\text { Silenciamento do Self" } \\
\text { é uma abordagem de } \\
\text { gênero, fruto de estudo } \\
\text { longitudinal com } \\
\text { mulheres com depressão, } \\
\text { seus relacionamentos, } \\
\text { principalmente com } \\
\text { homens - sobre } \\
\text { como silenciam sobre } \\
\text { pensamentos, sentimentos } \\
\text { e as ações que gostariam } \\
\text { de realizar para não se } \\
\text { contrapor aos desejos de } \\
\text { seu parceiro. }\end{array}$ & $\begin{array}{l}\text { Reuniões mensais para compartilhar a preocupação } \\
\text { com alto índice de HIV na comunidade, e aumentar a } \\
\text { consciência de enormes desigualdades no campo da } \\
\text { saúde. Compartilhou-se o conhecimento acumulado no } \\
\text { grupo, as dificuldades de negociação de sexo seguro e } \\
\text { se apresentou para a reflexão a teoria do Silenciamento } \\
\text { do Self. } \\
\text { Intervenção foi estruturada para escrita, conversas, } \\
\text { produção de filmes sobre episódios biográficos e } \\
\text { negativos, que eram então escritos. } \\
\text { Realizada por professores universitário na área da saúde } \\
\text { pública e da enfermagem e por pares. }\end{array}$ & $\begin{array}{c}\text { Mulheres negras } \\
\text { de baixa renda, } \\
\text { em processo de } \\
\text { envelhecimento, } \\
\text { vulneráveis ou } \\
\text { infectadas pelo } \\
\text { HIV }\end{array}$ & $\begin{array}{c}\text { Ensaio descritivo sobre o } \\
\text { processo }\end{array}$ \\
\hline $\begin{array}{c}6 \\
\text { Gist }\end{array}$ & $\begin{array}{l}\text { Pergunta do artigo: } \\
\text { como o "feminismo } \\
\text { negro" (conceito, } \\
\text { teoria aplicada e } \\
\text { rede de proteção) } \\
\text { funciona para } \\
\text { auxiliar estudantes a } \\
\text { entender as múltiplas } \\
\text { formas pelas quais } \\
\text { as mulheres negras } \\
\text { ou pardas são } \\
\text { marginalizadas por } \\
\text { práticas e estruturas } \\
\text { institucionalizadas? }\end{array}$ & $\begin{array}{c}\text { Embasado fortemente } \\
\text { na obra de Patricia } \\
\text { Hill Collins que define } \\
\text { uma pedagogia crítica } \\
\text { e feminista negra, que } \\
\text { pensa a sala de aula } \\
\text { como espaço para } \\
\text { transformação coletiva e } \\
\text { pessoal, numa perspectiva } \\
\text { emancipatória. }\end{array}$ & $\begin{array}{l}\text { Intervenção em sala de aula: planejamento detalhado } \\
\text { de aulas para produzir "consciência crítica" sobre } \\
\text { padrões de desigualdade (de gênero, raça e econômica) } \\
\text { utilizando a leitura de autoras negras e feministas, que } \\
\text { permitam interpelar teorias de "sucesso individual" e } \\
\text { sair da posição de auto-acusação pelo fracasso pessoal } \\
\text { sem entender o contexto e reinterpretando o "mundo } \\
\text { perigoso" da sala de aula. Permite que professores e } \\
\text { estudantes pensem criticamente como mulheres negras } \\
\text { estão situadas como agentes sociais na sociedade, } \\
\text { mesmo em contextos institucionais que mantém } \\
\text { privilégios de certos grupos. } \\
\text { Realizada por professoras. }\end{array}$ & $\begin{array}{c}\text { Professores e } \\
\text { estudantes em } \\
\text { geral, dedicadas } \\
\text { a prevenir } \\
\text { sofrimento de } \\
\text { mulheres negras. }\end{array}$ & $\begin{array}{c}\text { Trata-se da descrição, } \\
\text { uma narrativa ensaísta } \\
\text { sobre a fundamentação } \\
\text { do projeto e a proposta } \\
\text { de intervenção } \\
\text { desenhada. } \\
\text { Não se apresenta } \\
\text { metodologia de pesquisa } \\
\text { ou projeto que o } \\
\text { estude. Mas há detalhes } \\
\text { sobre o que deve ser a } \\
\text { intervenção e planos } \\
\text { de aula detalhados para } \\
\text { atingir os objetivos. }\end{array}$ \\
\hline
\end{tabular}

(continua) 
(continuação)

\begin{tabular}{|c|c|c|c|c|c|}
\hline Artigo & Objetivos & Perspectiva teórica & Descrição e Realização & Participantes & $\begin{array}{l}\text { Métodos, técnicas } \\
\text { e instrumentos }\end{array}$ \\
\hline $\begin{array}{c}7 \\
\text { González- } \\
\text { Prende } \\
.\end{array}$ & $\begin{array}{l}\text { Analisar os efeitos de } \\
\text { uma intervenção de } \\
\text { grupos de manejo da } \\
\text { raiva de curta duração } \\
\text { (8 sessões, presenci- } \\
\text { ais) para reabilitação } \\
\text { do abuso de álcool e/ } \\
\text { ou drogas. O estudo } \\
\text { avaliou o impacto } \\
\text { do tratamento no } \\
\text { nível do traço raiva } \\
\text { (Spielberger, 1988) } \\
\text { das participantes e no } \\
\text { modelo atributivo }\end{array}$ & $\begin{array}{l}\text { Teoria Cognitivo- } \\
\text { Comportamental } \\
\text { e Teoria da } \\
\text { Atribuição } \\
\text { (que identifica como } \\
\text { as pessoas atribuem } \\
\text { sentido /causas ao } \\
\text { comportamento dos } \\
\text { outros. Empodera- } \\
\text { mento foi tema recor- } \\
\text { rente para ajudar as } \\
\text { mulheres aumentar } \\
\text { auto-determinação, } \\
\text { auto eficácia e } \\
\text { expandir suas oportu- } \\
\text { nidades (de Zastrow } \\
\text { \& Kirst-Ashman, } \\
\text { 2004). }\end{array}$ & $\begin{array}{l}\text { Detalhada descrição de } 2 \text { tipos de aconsel- } \\
\text { hamento em } 8 \text { sessões de grupo com foco } \\
\text { no manejo da raiva. } \\
\text { Um grupo recebeu um tratamento } \\
\text { cognitivo-comportamental presencial de } \\
\text { manejo da raiva. Outro grupo recebeu um } \\
\text { tratamento de prevenção de recaída com } \\
\text { duração de oito semanas sem o componente } \\
\text { de manejo de raiva. Usou-se roleplaying e } \\
\text { debate as sessões abordaram temas como: } \\
\text { 1) identificar a influência do pensamento } \\
\text { nas emoções; 2) identificar as idiossincra- } \\
\text { sias pessoais que aumentam sentimentos } \\
\text { de raiva; 3) reconhecer suas crenças e } \\
\text { outras explicações alternativas plausíveis; } \\
\text { 4) reconhecer indicadores de que "lá vem a } \\
\text { raiva"; 5) aumentar a responsabilidade por } \\
\text { suas emoções e comportamentos por auto- } \\
\text { monitoramento; 6) técnicas de relaxamento; } \\
\text { 7) treinamento de capacidade para comuni- } \\
\text { cação assertiva e resolução de conflitos. } \\
\text { Realizado pelo autor }\end{array}$ & $\begin{array}{l}\text { Predominantemente, } \\
\text { mulheres afro- } \\
\text { americanas, de nível } \\
\text { socioeconômico } \\
\text { baixo, morando } \\
\text { preferencialmente } \\
\text { em instalações } \\
\text { residenciais no } \\
\text { centro-oeste da } \\
\text { cidade de Detroit, } \\
\text { em reabilitação do } \\
\text { abuso de álcool e } \\
\text { drogas. }\end{array}$ & $\begin{array}{l}\text { O desenho consiste } \\
\text { em dois grupos } \\
\text { aleatoriamente } \\
\text { atribuídas em duas } \\
\text { opções de trata- } \\
\text { mento e avaliação } \\
\text { antes e depois do } \\
\text { tratamento. }\end{array}$ \\
\hline
\end{tabular}


(continuação)

\begin{tabular}{|c|c|c|c|c|c|}
\hline Artigo & Objetivos & Perspectiva teórica & Descrição e Realização & Participantes & Métodos, técnicas e instrumentos \\
\hline $\begin{array}{c}8 \\
\text { Nicol }\end{array}$ & $\begin{array}{l}\text { Descrição de como } \\
\text { integrei imagens de } \\
\text { mulheres negras na } \\
\text { mídia e na cultura } \\
\text { a fim de auxiliar } \\
\text { estudantes a contestar } \\
\text { as representações } \\
\text { limitadas, falsas e } \\
\text { distorcidas das vidas } \\
\text { diárias. }\end{array}$ & $\begin{array}{c}\text { Teoria de Três pontas } \\
\text { para análise cultural: } \\
\text { produção, consumo e } \\
\text { agência }\end{array}$ & $\begin{array}{l}\text { Teoria de Três pontas para análise } \\
\text { cultural: produção, consumo e agência }\end{array}$ & $\begin{array}{c}\text { Estudantes de } \\
\text { mestrado no curso } \\
\text { de Estudos sobre } \\
\text { mulheres }\end{array}$ & $\begin{array}{l}\text { Ensaio escrito na 1a pessoa do } \\
\text { singular, como relato de experiência }\end{array}$ \\
\hline $\begin{array}{c}9 \\
\text { Oliveira e } \\
\text { cols }\end{array}$ & $\begin{array}{l}\text { Compreender } \\
\text { os efeitos da } \\
\text { discriminação racial } \\
\text { na identidade e } \\
\text { subjetividade de } \\
\text { mulheres negras } \\
\text { atendidas no } \\
\text { programa SOS } \\
\text { Racismo, em Porto } \\
\text { Alegre/RS, Brasil. } \\
\text { Ouvir as narrativas } \\
\text { das mulheres que } \\
\text { sofreram atos de } \\
\text { racismo/discriminação } \\
\text { e agenciar outras } \\
\text { referências } \\
\text { identitárias. }\end{array}$ & $\begin{array}{l}\text { Análise das práticas } \\
\text { discursivas, entendidas } \\
\text { como a forma pela } \\
\text { quais as pessoas } \\
\text { produzem sentidos para } \\
\text { experiências como as } \\
\text { da violência racial. } \\
\text { Referencial teórico dos } \\
\text { estudos de gênero. }\end{array}$ & $\begin{array}{l}\text { A organização não-governamental } \\
\text { (ONG) oferece atendimento jurídico } \\
\text { contra o crime de racismo, atendimento } \\
\text { psicossocial aos prejuízos emocionais } \\
\text { causados pela violência da discriminação } \\
\text { e atenção interdisciplinar para o } \\
\text { fortalecimento da identidade racial das } \\
\text { beneficiárias, agenciando outros modos } \\
\text { de subjetivação. } \\
\text { Estratégia de grupos dispositivos } \\
\text { (processo grupal como possibilidade de } \\
\text { transformação social), atento ao jogo } \\
\text { de interesses e de poder no campo da } \\
\text { pesquisa. } \\
\text { Realizada pelas autoras, que inclui uma } \\
\text { militante do movimento de mulheres } \\
\text { negras. }\end{array}$ & $\begin{array}{l}\text { Mulheres negras } \\
\text { atendidas pelo } \\
\text { Programa SOS } \\
\text { Racismo }\end{array}$ & $\begin{array}{l}\text { Desenho qualitativo e texto } \\
\text { descritivo do material empírico } \\
\text { das atividades de grupo de } \\
\text { mulheres negras que denunciaram } \\
\text { a discriminação racial no programa } \\
\text { SOS. } \\
\text { Três sessões de grupo de uma hora, } \\
\text { por } 3 \text { semanas sobre: (1) relatos } \\
\text { sobre as histórias de vida; (2) o que } \\
\text { significa ser mulher negra nesse } \\
\text { contexto histórico e social: por meio } \\
\text { de fotografias das participantes do } \\
\text { grupo e de portfólios de mulheres } \\
\text { negras, acionou-se referências } \\
\text { identitárias afro-brasileiras; (3) } \\
\text { compartilhamento de narrativas de } \\
\text { resistência, relatos de transgressões } \\
\text { e subversões ao modelo racial } \\
\text { hegemônico }\end{array}$ \\
\hline
\end{tabular}

(continua) 
(continuação)

\begin{tabular}{|c|c|c|c|c|c|}
\hline Artigo & Objetivos & $\begin{array}{l}\text { Perspectiva } \\
\text { teórica }\end{array}$ & Descrição e Realização & Participantes & $\begin{array}{l}\text { Métodos, técnicas e instrumen- } \\
\text { tos }\end{array}$ \\
\hline $\begin{array}{c}10 \\
\text { Sheppard } \\
\text { e cols }\end{array}$ & $\begin{array}{l}\text { Testar uma intervenção } \\
\text { por pares com mulheres } \\
\text { negras com câncer de } \\
\text { mama - "tratamento } \\
\text { centrado no paciente": } \\
\text { Sisters Informing Sisters } \\
\text { O objetivo é ajudar } \\
\text { mulheres a obter } \\
\text { informações necessária } \\
\text { de seus médicos } \\
\text { para tomar decisões } \\
\text { apropriadas a seus } \\
\text { valores, preferências e } \\
\text { necessidades. }\end{array}$ & $\begin{array}{c}\text { Perspectiva } \\
\text { sociocognitiva } \\
\text { que inclui o } \\
\text { fortalecimento } \\
\text { da agência das } \\
\text { mulheres. }\end{array}$ & $\begin{array}{l}\text { Intervenção composta por sessões de educação } \\
\text { por pares entre mulheres negras para a construção } \\
\text { do perguntar e se comunicar melhor, para ter } \\
\text { melhor habilidades de lidar com o câncer de } \\
\text { mama: TALK:Tell your story, Ask questions, } \\
\text { Listen actively, and Know your options (conte sua } \\
\text { história, pergunte, escute ativamente e conheça } \\
\text { suas opções). } \\
\text { Reúne uma paciente recém diagnosticada de } \\
\text { câncer de mama e uma sobrevivente capacitada } \\
\text { para uma sessão presencial educativa sobre } \\
\text { habilidades. } \\
\text { Realizada pelas autoras. }\end{array}$ & $\begin{array}{l}\text { Mulheres que se identificam } \\
\text { como negras, com } \\
\text { confirmação histológica do } \\
\text { câncer de mama, e mais de } \\
21 \text { anos em qualquer estágio } \\
\text { do câncer. Mulheres com } \\
\text { câncer de mama recorrente } \\
\text { ou que já tiveram outro tipo } \\
\text { de câncer anteriormente } \\
\text { foram excluídas, dado que a } \\
\text { tomada de decisão se torna } \\
\text { mais complexa para este } \\
\text { grupo. }\end{array}$ & $\begin{array}{l}\text { Após uma entrevista inicial via } \\
\text { telefone, as mulheres passaram por } \\
\text { uma sessão educacional presencial } \\
\text { de suporte à decisão, conduzida } \\
\text { por uma capacitada coach } \\
\text { sobrevivente. A coach utilizou } \\
\text { do guia culturalmente adaptado } \\
\text { e modelo de tomada de decisões } \\
\text { (TALK Back! C). Uma avaliação de } \\
\text { processo abordou: a aceitabilidade, } \\
\text { a satisfação com o material } \\
\text { impresso, e o relato das mulheres } \\
\text { sobre evolução de sua auto-eficácia } \\
\text { na comunicação com médicos, } \\
\text { na compreensão e decisão sobre } \\
\text { tratamento, e se foi um tratamento } \\
\text { centrado na cliente. }\end{array}$ \\
\hline $\begin{array}{c}9 \\
\text { Oliveira e } \\
\text { cols }\end{array}$ & $\begin{array}{l}\text { Analisa uma vivência } \\
\text { muito inovadora } \\
\text { no abastecimento } \\
\text { alimentício da cidade de } \\
\text { Detroit, por agricultura } \\
\text { urbana como uma } \\
\text { forma de retornarem } \\
\text { a suas raízes culturais } \\
\text { e reivindicar seu } \\
\text { poder, libertas das } \\
\text { restrições impostas pela } \\
\text { comercialização e pelo } \\
\text { consumismo. }\end{array}$ & $\begin{array}{c}\text { Mobilização, } \\
\text { educação, } \\
\text { defesa de } \\
\text { políticas } \\
\text { públicas e } \\
\text { melhorias } \\
\text { materiais no } \\
\text { bairro. }\end{array}$ & $\begin{array}{l}\text { Foram entrevistadas } 8 \text { mulheres (de } 30 \text { a } 60 \\
\text { anos), que são líderes comunitárias, educadoras, } \\
\text { funcionárias públicas do município ou } \\
\text { desempregadas/buscan-do trabalho. Três eram } \\
\text { fundadoras da organização, } 2 \text { trabalharam na } \\
\text { gestão e as } 3 \text { restantes eram voluntárias muito } \\
\text { ativas e envolvidas com atividades agrícolas. } \\
\text { Essas camponesas se posicionam como ativistas } \\
\text { pelo direito à segurança alimentar, por direitos dos } \\
\text { presidiários e das suas famílias, direitos digitais e } \\
\text { ambientais, educação comunitária e cidadã. } \\
\text { Responsáveis: mulheres negras e ativistas }\end{array}$ & -- & -- \\
\hline
\end{tabular}


(continuação)

\begin{tabular}{|c|c|c|c|c|c|}
\hline Artigo & Objetivos & Perspectiva teórica & Descrição e Realização & Participantes & $\begin{array}{l}\text { Métodos, técnicas e } \\
\text { instrumentos }\end{array}$ \\
\hline $\begin{array}{c}12 \\
\text { Wissman }\end{array}$ & $\begin{array}{c}\text { O que podemos } \\
\text { aprender a partir } \\
\text { da participação das } \\
\text { estudantes nesse } \\
\text { curso, como são } \\
\text { suas respostas a essa } \\
\text { tradição na escrita } \\
\text { e partilha de suas } \\
\text { próprias poesias. Quais } \\
\text { são os entendimentos } \\
\text { de uma "Heterotopia" } \\
\text { em um trabalho de } \\
\text { alfabetização de jovens } \\
\text { mulheres negras? De } \\
\text { que forma abraçaram } \\
\text { a oportunidade de } \\
\text { construir e experienciar } \\
\text { um curso eletivo } \\
\text { embasado na tradição } \\
\text { de mulheres afro- } \\
\text { americanas em } \\
\text { alfabetização? Como } \\
\text { colocaram suas } \\
\text { próprias experiências } \\
\text { vividas e identidades } \\
\text { sociais na interpretação } \\
\text { e escrita da poesia? }\end{array}$ & $\begin{array}{c}\text { Perspectivas } \\
\text { Espaciais (Leander } \\
\text { \& Sheehy, 2004), } \\
\text { "Outros Espaços" } \\
\text { (Foucault, 1986), } \\
\text { "Espaço Criativo } \\
\text { Radical", Tradições e } \\
\text { Poesias de Literatura } \\
\text { Afro-Americanas, } \\
\text { Teoria Realista } \\
\text { Pós-Positivista } \\
\text { e Epistemologia } \\
\text { Feminista Negra. }\end{array}$ & $\begin{array}{c}\text { Práticas que surgiram em um curso } \\
\text { escolar eletivo embasado na tradição } \\
\text { afro-americanas em alfabetização de e } \\
\text { por mulheres. } \\
\text { Realizada pela autora e escrito na 1a } \\
\text { pessoa do singular }\end{array}$ & $\begin{array}{c}\text { A maioria destes } \\
\text { estudantes são mulheres } \\
\text { negras. }\end{array}$ & $\begin{array}{c}\text { A metodologia } \\
\text { utilizada neste estudo } \\
\text { é fundamentada na } \\
\text { Practitioner enquiry } \\
\text { - (metodologia de } \\
\text { investigação pelo } \\
\text { professor com seus } \\
\text { alunos) e de pesquisa } \\
\text { feminista. Um } \\
\text { aspecto significativo } \\
\text { desta metodologia } \\
\text { é o de posicionar os } \\
\text { estudantes também } \\
\text { como criadores do } \\
\text { conhecimento, com } \\
\text { agência para informar } \\
\text { e mudar o trabalho } \\
\text { na sala de aula e na } \\
\text { pesquisa. }\end{array}$ \\
\hline
\end{tabular}


Em uma revisão de literatura que buscou inspiração para intervenções futuras a partir de um escopo das já realizadas, seria de se esperar que pudéssemos ter atendido a critérios para se medir ou afirmar o sucesso das experiências; no entanto, essa avaliação foi prejudicada pelo fato de os artigos terem temáticas e metodologias muito específicas e variadas, sendo difícil, assim, comparar os trabalhos e seus resultados. Uma característica observada é que os artigos que estão na tradição feminista ou na pedagogia crítica ressaltaram as lições aprendidas; os outros destacaram o desenho rigoroso da pesquisa e recomendaram estudos randomizados e controlados cuja unidade de análise permanece sendo o indivíduo biológico-comportamental.

É possível identificar, por exemplo, resultados individuais para mazelas pontuais. Por exemplo, Andrews e cols. (2007) indicam grande sucesso, pois cerca de $30 \%$ das mulheres sustentaram o "parar de fumar". O resultado que consideram satisfatório é explicado por medidas intermediárias e conquistas individuais, como o aumento do apoio social e da autoeficácia. Cooper e cols. (2015) observaram mudanças nas medidas das mulheres da comunidade religiosa aderidas ao projeto para emagrecer, testemunhos de realização e comprometimento com mudança, influenciados pelo apoio mútuo; para além desses sucessos, apenas ressaltam que grupos comunitários, como as igrejas, podem ser espaços para promoção da saúde individual. Sheppard e cols. (2013) observaram aumento de 70\% na eficácia de comunicação entre mulheres com câncer de mama e profissionais de saúde, além de maior autoeficácia pessoal nas suas tomadas de decisão quanto ao tratamento.

Como se pode observar, a maioria dos estudos tem desenho etnográfico ou são ensaios sobre a experiência de intervenção. Muitos narram, em primeira pessoa, a experiência de algumas mulheres negras cuidando de outras. A tradição feminista negra se expressa também na escolha deste tipo de escrita, além de constar nas referências teóricas, como discute Wane (2009). As recomendações insistem na continuidade das intervenções e na atenção às especificidades dos resultados associados às particularidades do contexto e do grupo atendido. De modo geral, abrem mão de pretensões universalistas.

O artigo de Bair (2008) descreve uma experiência histórica, conduzida por Burroughs, de educação para emancipação de mulheres negras, em sintonia com 
(possivelmente inspirando) muitas intervenções estadunidenses posteriores. No trabalho das autoras estadunidenses, assim como em hooks (2013), encontramos muitas intervenções educativas, pedagogias críticas e voltadas para emancipação, em projetos que intervêm ou pretendem inspirar outras intervenções voltadas para benefícios individuais, ou de determinado segmento social, ou do território onde vivem.

Já no artigo brasileiro, de Oliveira e cols. (2009), o único do Sul global encontrado na revisão, a análise multidimensional se destaca pela ambição de institucionalizar as lições aprendidas, na busca por agenciar outras referências identitárias. Inclui a dimensão programática e institucional das vulnerabilidades ao adoecimento e a necessidade de aprimorar políticas públicas e de estado, para mitigar a vulnerabilidade das mulheres negras ao sofrimento psicossocial resultante de racismo e discriminação. Essa especificidade de pensar políticas públicas e programas também apareceu fortemente nas estratégias reconhecidas no movimento negro e de mulheres negras, coletadas por entrevistas, e que não temos espaço de incluir aqui (ver Prestes, 2018).

Ayres, Paiva e França Júnior (2012) também compreendem o processo saúdedoença como multidimensional, concebendo a vulnerabilidade em suas dimensões individual, social e programática, ou seja, um processo de adoecimento estará mediado por contexto de maior ou menor vulnerabilidade baseado na trajetória individual, nas interações estruturadas socialmente, nas particularidades de cada território ou na qualidade dos programas sustentáveis de mitigação da vulnerabilidade ao adoecimento, entre outros.

A concepção de uma interconexão de fatores está presente também nos artigos com perspectiva teórica inspirada no feminismo negro, como é o caso de Bair (2008), Barlow (2016), Gist (2016), Oliveira e cols. (2009) e Wissman (2011). Um dos principais conceitos dessa perspectiva é a interseccionalidade, que, como defendem Collins (2015, 2009), Cardoso (2012) e Crenshaw (2002), serve como ferramenta analítica de compreensão da saúde de mulheres negras composta por uma multiplicidade de fatores mutuamente influentes, que passam por raça, gênero, classe, orientação sexual, habilidades/deficiências, nacionalidade, regionalidade, geração, entre outros. 
Em uma revisão de literatura que buscou inspiração para intervenções futuras a partir de um escopo das já realizadas, seria de se esperar que pudéssemos ter atendido a critérios para se medir ou afirmar o sucesso das experiências; no entanto, essa avaliação foi prejudicada pelo fato de os artigos terem temáticas e metodologias muito específicas e variadas, sendo difícil, assim, comparar os trabalhos e seus resultados. Uma característica observada é que os artigos que estão na tradição feminista ou na pedagogia crítica ressaltaram as lições aprendidas; os outros destacaram o desenho rigoroso da pesquisa e recomendaram estudos randomizados e controlados cuja unidade de análise permanece sendo o indivíduo biológico-comportamental.

É possível identificar, por exemplo, resultados individuais para mazelas pontuais. Por exemplo, Andrews e cols. (2007) indicam grande sucesso, pois cerca de 30\% das mulheres sustentaram o "parar de fumar". O resultado que consideram satisfatório é explicado por medidas intermediárias e conquistas individuais, como o aumento do apoio social e da autoeficácia. Cooper e cols. (2015) observaram mudanças nas medidas das mulheres da comunidade religiosa aderidas ao projeto para emagrecer, testemunhos de realização e comprometimento com mudança, influenciados pelo apoio mútuo; para além desses sucessos, apenas ressaltam que grupos comunitários, como as igrejas, podem ser espaços para promoção da saúde individual. Sheppard e cols. (2013) observaram aumento de 70\% na eficácia de comunicação entre mulheres com câncer de mama e profissionais de saúde, além de maior autoeficácia pessoal nas suas tomadas de decisão quanto ao tratamento.

Como se pode observar, a maioria dos estudos tem desenho etnográfico ou são ensaios sobre a experiência de intervenção. Muitos narram, em primeira pessoa, a experiência de algumas mulheres negras cuidando de outras. A tradição feminista negra se expressa também na escolha deste tipo de escrita, além de constar nas referências teóricas, como discute Wane (2009). As recomendações insistem na continuidade das intervenções e na atenção às especificidades dos resultados associados às particularidades do contexto e do grupo atendido. De modo geral, abrem mão de pretensões universalistas.

O artigo de Bair (2008) descreve uma experiência histórica, conduzida por Burroughs, de educação para emancipação de mulheres negras, em sintonia com 
(possivelmente inspirando) muitas intervenções estadunidenses posteriores. No trabalho das autoras $^{6}$ estadunidenses, assim como em hooks ${ }^{7}$ (2013), encontramos muitas intervenções educativas, pedagogias críticas e voltadas para emancipação, em projetos que intervêm ou pretendem inspirar outras intervenções voltadas para benefícios individuais, ou de determinado segmento social, ou do território onde vivem.

Já no artigo brasileiro, de Oliveira e cols. (2009), o único do Sul global encontrado na revisão, a análise multidimensional se destaca pela ambição de institucionalizar as lições aprendidas, na busca por agenciar outras referências identitárias. Inclui a dimensão programática e institucional das vulnerabilidades ao adoecimento e a necessidade de aprimorar políticas públicas e de estado, para mitigar a vulnerabilidade das mulheres negras ao sofrimento psicossocial resultante de racismo e discriminação. Essa especificidade de pensar políticas públicas e programas também apareceu fortemente nas estratégias reconhecidas no movimento negro e de mulheres negras, coletadas por entrevistas, e que não temos espaço de incluir aqui (ver Prestes, 2018).

Ayres, Paiva e França Júnior (2012) também compreendem o processo saúdedoença como multidimensional, concebendo a vulnerabilidade em suas dimensões individual, social e programática, ou seja, um processo de adoecimento estará mediado por contexto de maior ou menor vulnerabilidade baseado na trajetória individual, nas interações estruturadas socialmente, nas particularidades de cada território ou na qualidade dos programas sustentáveis de mitigação da vulnerabilidade ao adoecimento, entre outros.

A concepção de uma interconexão de fatores está presente também nos artigos com perspectiva teórica inspirada no feminismo negro, como é o caso de Bair (2008), Barlow (2016), Gist (2016), Oliveira e cols. (2009) e Wissman (2011). Um dos principais conceitos dessa perspectiva é a interseccionalidade, que, como defendem Collins (2015, 2009), Cardoso (2012) e Crenshaw (2002), serve como ferramenta analítica de compreensão da saúde de mulheres negras composta por uma multiplicidade de fatores mutuamente influentes, que passam por raça, gênero, classe, orientação sexual, habilidades/deficiências, nacionalidade, regionalidade, geração, entre outros. 
A compreensão multidimensional presente nesses estudos soma na direção do enfrentamento da colonialidade de poder que, segundo Santos (2015), não poderá ser rompida com considerações unidimensionais da opressão e da liberdade. É necessário acionar um deslocamento dos centros hegemônicos de poder, pela conjugação de diferentes vozes, discursos, estilos de ação e pensamento, assim como de diferentes estratégias de enfrentamento e superação empenhadas por mulheres negras, como também argumenta hooks (2000).

Nesse sentido, a pesquisa que inspira este texto adotou um desenho metodológico de encruzilhada entre diferentes discursos, tendo a interseccionalidade como ferramenta analítica, como defendido por Cardoso (2012), Collins (2015, 2009) e esta com Bilge (2016), e também como método de ação. Diferentes fontes de conhecimento contribuíram para um panorama de estratégias reconhecidas não apenas no âmbito científico, mas também no campo do movimento negro e de mulheres negras.

A necessidade de descrever essas experiências justificaria não termos restringido o filtro a artigos, e expandir a inclusão para as literaturas denominadas cinzentas, que são textos variados como teses, livros, relatórios, entre outros, onde costumam constar as produções não científicas. Considerando-se apenas a tradição dos protocolos de revisão sistemática de escopo, não ter ampliado para a literatura cinzenta seria um limite da pesquisa. As produções do movimento social foram garantidas, no entanto, nos conteúdos coletados pelas entrevistas com informantes-chave desse campo. E, se ampliássemos para além dos artigos, não atenderíamos ao critério que adotamos para definir o que se pode considerar como reconhecido no campo científico, ou seja, artigos validados por pares, além de termos apenas um tipo de fonte de consulta.

O interessante foi notar que, apesar dessa separação na busca, as experiências do campo científico tinham considerável influência do campo do movimento negro e de mulheres negras, e que as deste último campo, por sua vez, eram todas de pessoas que acumulavam formação militante e acadêmica. Entendemos que essa confluência dos discursos - acadêmico e do movimento social - não é por acaso, pois tanto a amostra de autoras quanto a de entrevistadas foi formada por uma maioria de mulheres negras ${ }^{8}$, as quais, muitas vezes, posicionam-se de forma identitária e politizada em suas práticas 
e publicações. O diálogo entre essas duas produções de conhecimento é defendido por Curiel (2007) e Collins e Bilge (2016).

O que pensar do fato de que, na revisão sistemática, dentre as mais de oito centenas de artigos analisados, apenas doze tratavam de estratégias voltadas à saúde de mulheres negras? A grande maioria, ocupava-se das mazelas, doenças e prejuízos vividos por mulheres negras, sem grandes reflexões sobre as causas, sem relatar processos de apoio e fortalecimento e sem derivar propostas práticas voltadas à promoção da saúde.

Racismo e sexismo interseccionados não apenas influenciam essa situação no campo acadêmico, ainda dominado por pesquisadores homens e brancos, mas também são parte significativa das condições sócio-históricas que produzem a maior vulnerabilidade ao adoecimento, invisíveis para os atores principais na produção da ciência. A maior parte dos artigos que lemos, na fase de seleção, apenas se debruçavam sobre a condição das mulheres negras constatando os prejuízos, sem apresentarem um volume significativo de intervenções para mudar essa realidade - embora falassem sobre empoderamento, resiliência, agência, autonomia e emancipação.

Nas centenas de artigos, raça e gênero aparecem como recortes descritivos da população atendida, mas desarticulados de discussões sobre suas especificidades. Raramente aparecem como recortes analíticos que explicam porque as mulheres negras estão super-representadas em amostras de grupos sociais em grande vulnerabilidade ou sem garantia de direitos. Os recortes de gênero e raça praticamente não aparecem também como aspectos para os quais se dedica atenção na formulação das intervenções ou na discussão dos resultados. A ciência, quando não trabalha com os recortes de especificidades, atende ao que se convencionou chamar de neutro, mas que, na verdade, é o hegemônico, enquanto anula as produções de outras fontes de conhecimento, praticando o epistemicídio, como formulam Boaventura de Sousa Santos (2007) e Sueli Carneiro (2011).

No número reduzido de práticas voltadas a processos saudáveis, as autorias são quase sempre de grupos que incluem ou são liderados por mulheres negras, a formular questões de pesquisa, valorizar as demandas, escutar as vozes de outras mulheres negras em seus estudos, e derivar roteiros de promoção da sua saúde. Daí a importância de diversidade na composição das equipes de pesquisa e nos referenciais teóricos. 
Santos (2015, p. 161) valoriza a conciliação de diferentes vozes, exemplificada no diálogo entre o feminismo e o pós-colonialismo:

Os estudos pós-coloniais em uma perspectiva feminista revelam um quadro teórico que ilustra as experiências históricas, sociais, políticas, culturais e econômicas das mulheres negras que assumem uma ótica diaspórica, internacional, já que se apoia no estudo das narrativas de mulheres negras imigrantes, residentes, de diferentes partes da África, mas também se apoia no estudo das teorias desenvolvidas por autores que se debruçaram sobre o tema gênero e raça em diferentes países.

A partir destas experiências focalizadas na sabedoria, habilidades e esforços de mulheres negras, Wane definiu os princípios sendo: a organização, o coletivismo, a resistência, o respeito mútuo, a produção de conhecimento, o armazenamento do conhecimento, divulgação da cultura, a reciprocidade, a autodeterminação, resiliência, cuidados com a comunidade, maternagem, fortalecimento mútuo, autoconfiança e espiritualidade.

Para agendas futuras, retomando Prestes (2018), recomendamos pesquisas que se atentem para a interseccionalidade como método de análise e de ação (COLLINS, 2015, 2009; CARDOSO, 2012; CRENSHAW, 2002); que considerem produções teóricas de diversas regiões, como as epistemologias do Sul (SANTOS, 2007), ou as cosmovisões andinas e amazônicas como o bem viver (ALCANTARA, 2017; ACOSTA, 2016; SALAZAR, 2016), em diálogo com demandas específicas (JUREMA; IRACI; CRUZ, 2015), que a saúde de mulheres negras seja assumida amplamente e não apenas pelas próprias.

Importante, também, fortalecer as estratégias de promoção de saúde desenvolvidas por mulheres negras, incluindo as experiências não acadêmicas (HOOKS, 2015), tendo o feminismo negro como estratégico para o enfrentamento das colonialidades de poder (WANE, 2008, 2009). Recomendamos, ainda, diversidade na formação das equipes e nas fontes teóricas, ampliar as publicações de pesquisadoras(es) negras(os), incluindo as produções do movimento negro e de mulheres negras, fomentar publicações sobre o assunto, além de garantir e ampliar as vozes de mulheres negras e a valorização de suas produções intelectuais (HOOKS, 1995), assim como as vozes de autoras(es) amefricanas(os) de modo geral, como diria Gonzalez (RATTS, 2010). 


\section{Tabela 1 - Referências dos artigos selecionados na revisão sistemática de escopo}

ANDREWS, Jeannette O.; FELTON, Gwen; WEWERS, Mary Ellen; WALLER, Jennifer; TINGEN, Martha. The Effect of a Multi-Component Smoking Cessation Intervention in African American Women Residing in Public Housing. Research in Nursing \& Health. 30, 45-60; 2007.

BAIR, Sarah D. Educating Black Girls in the Early 20th Century: the pioneering work of nannie helen burroughs (1879-1961). Theory \& Research in Social Education, 36:1, 9-35; 2008.

BARLOW, Jameta N. \#WhenIFellInLoveWithMyself: disrupting the gaze and loving our black womanist self as an act of political warfare. Meridians: feminism, race, transnationalism. 15:1: 205-217; 2016.

COOPER, Kami C.; KING, Michalene A.; SARPONG, Daniel F. Tipping the Scales on Obesity: church-based health promotion for african american women. Journal of Christian Nursing. 32(1), 41-45; 2015.

DEMARCO, Rosanna F.; LANIER, Latrona R. The Concept of "Silencing the Self" in Low-Income, Aging, HIV-Infected African American Women: a 10-year community-based participatory programof research with results. Journal Of The Association Of Nurses In Aids Care. 25: 2, 112-122; 2014.

GIST, Conra D. A Black Feminist Interpretation: reading life, pedagogy, and emilie. $M e$ ridians: feminism, race, transnationalism. 15:1, 245-289; 2016.

GONZÁLEZ-PRENDES, Antonio. Anger-Control Group Counseling for Women Recovering From Alcohol or Drug Addiction. Research on Social Work Practice. 18:6, 616-625; 2008.

NICOL, Donna J. Teaching Analysis and Agency Using Racist and Sexist Imagery: implications for cultural studies in the college classroom. Feminist Teacher. 22: 2, 89-107; 2012.

OLIVEIRA, Maria Luísa Pereira de; MENEGHEL, Stela Nazareth; BERNARDES, Jefferson Bernardes. Modos de subjetivação de mulheres negras: efeitos da discriminação racial. Psicologia \& Sociedade; 21 (2): 266-274, 2009.

SHEPPARD. Vanessa B.; WALLINGTON, Sherrie F.; WILLEY, Shawna C.; HAMPTON, Regina M.; LUCAS, W; JENNINGS, Y; HORTON, S.; MUZECK, N.; COCILOVO, C.; ISAACS, C. A Peer-Led Decision Support Intervention Improves Decision Outcomes in Black Women with Breast Cancer. Journal of Cancer Education. 28:262-269; 2013.

WHITE, Monica M. Sisters of the Soil: Urban Gardening as Resistance in Detroit Race/ Ethnicity: Multidisciplinary Global Contexts, 5:1,13-28, 2011.

WISSMAN, Kelly. "Rise Up!": Literacies, Lived Experiences, and Identities within an In-School "Other Space". Research in the Teaching of English. 45: 4, 2011. 


\section{Referências}

AYRES, José Ricardo; PAIVA, Vera; FRANÇA Júnior, Ivan. Conceitos e práticas de prevenção: da história natural da doença ao quadro da vulnerabilidade e direitos humanos. In: PAIVA, Vera; AYRES, José Ricardo; BUCHALLA, Cassia Maria (Org.). Vulnerabilidade e direitos humanos: prevenção e promoção da saúde [Coletânea]. Livro 1: Da doença à cidadania. Curitiba: Juruá, 2012.

CARDOSO, Cláudia Pons. Outras falas: feminismos na perspectiva de mulheres negras brasileiras. Salvador: UFBA, 2012. Tese (Doutorado em Estudos Interdisciplinares sobre Mulheres, Gênero e Feminismo) - Programa de Pós- Graduação em Estudos de Gênero, Mulher e Feminismo. Universidade Federal da Bahia, Salvador, 2012.

CARNEIRO, Sueli. Racismo, sexismo e desigualdade no Brasil. São Paulo: Selo Negro, 2011.

COLLINS, Patricia Hill. Black feminist thought: knowledge, consciousness and the politics of empowerment. 2nd ed. New Your and London: Routledge, 2009.

. Em relação a uma nova visão: raça, classe e gênero como categorias de análise e conexão. In: MORENO, Renata (Org.). Reflexões e práticas de transformação feminista. São Paulo: SOF, 2015.

; BILGE, Sirma. Intersectionality. Cambridge: Polity Press, 2016.

CRENSHAW, Kimberlé. Documento para o encontro de especialistas em aspectos da discriminação racial relativos ao gênero. Revista Estudos Feministas. Florianópolis, v. 10, n. 1, p. 171-188, jan. 2002.

CURIEL, Ochy. Crítica poscolonial desde las prácticas políticas del feminismo antirracista. Nómadas. Bogotá, p. 92-101, abr. 2007.

HOOKS, Bell. Ensinando a transgredir: a educação como prática da liberdade. São Paulo: WMF Martins Fontes, 2013.

. Feminist theory: from margin to center. 2 ed. Cambridge: South End Press, 2000.

. Intelectuais Negras. Revista Estudos Feministas, Florianópolis, v. 3, n. 2, p. 464, jan. 1995.

. Sisters of the yam: black women and self-recovery. 3rd ed. New York: Routledge, $2015 \mathrm{~b}$.

PRESTES, Clélia R. S. Estratégias de promoção da saúde de mulheres negras: interseccionalidade e bem viver. 2018. 206 f. Tese (Doutorado em Ciências - Psicologia Social) - Instituto de Psicologia, Universidade de São Paulo, São Paulo, 2018.

RATTS, Alex. As amefricanas: mulheres negras e feminismo na trajetória de Lélia Gonzalez. Fazendo Gênero 09: Diásporas, diversidades e deslocamentos. Santa Catarina: 2010.

SALAZAR, Adriana Rodríguez. Teoría y práctica del buen vivir: orígenes, debates con- 
ceptuales y conflictos sociales. El caso de Ecuador. 2016. 421 f. Tese (Doutorado) - Universidad del País Vasco. Espanha, 2016.

SANTOS, Boaventura de Sousa. Renovar a teoria crítica e reinventar a emancipação social. São Paulo: Boitempo, 2007.

SANTOS, Gislene Aparecida dos. Racismo institucional: uma análise a partir da perspectiva dos estudos pós-coloniais e da ética. Ensaios Filosóficos, v. 11, jul. 2015.

WANE, Njoki. Mapping the field of Indigenous knowledges in anti-colonial discourse: a transformative journey in education. In: Race Ethnicity and Education, 11:2,2008, p. 183-197.

WANE, Njoki. Black Canadian feminist thought: perspectives on equity and diversity in the academy. In: Race Ethnicity and Education, 12:1, 2009, p. 65-77.

WERNECK, Jurema; IRACI, Nilza; CRUZ, Simone. Marcha das mulheres negras. Fundação Ford, 2015.

\section{Notas}

${ }^{1}$ Contribuição das autoras: Prestes realizou a pesquisa de doutorado, que inspirou e sustentou este artigo. Paiva, sua orientadora, contribuiu na concepção do artigo, em todas as etapas. Fachim contribui na concepção, na etapa de revisão do texto. Os três coproduziram a revisão de literatura, a reflexão e a revisão sistemática de escopo da pesquisa, necessária para a construção do artigo.

${ }^{2}$ Universidade de São Paulo. Instituto de Psicologia. Departamento de Psicologia Social. São Paulo, SP, Brasil. Instituto AMMA Psique e Negritude. São Paulo, SP, Brasil. E-mail: cleli@usp.br

${ }^{3}$ Pontifícia Universidade Católica de São Paulo. Faculdade de Educação. Programa de Estudos Pós-graduados em Educação: Psicologia da Educação. São Paulo, SP, Brasil. E-mail: fefachim@gmail.com

${ }^{4}$ Universidade de São Paulo. Instituto de Psicologia. Departamento de Psicologia Social. São Paulo, SP, Brasil. E-mail: veroca@usp.br

5 Essa pesquisa (assim como o estágio doutoral) foi realizada com apoio da Coordenação de Aperfeiçoamento de Pessoal de Nível Superior - Brasil (CAPES) - Código de Financiamento 001.

${ }^{6}$ A maioria das autorias dos artigos selecionados é de mulheres; o mesmo ocorre com as pessoas entrevistadas. Por isso, adotamos o gênero feminino como neutro na referência às autoras e às entrevistadas.

7 A grafia em minúsculas é uma escolha da autora, para defender o destaque ao conteúdo, mais que ao sobrenome de quem escreve.

${ }^{8}$ Atribuímos às autoras uma classificação racial a partir de imagens disponíveis na internet e de algumas afirmações de pertencimento presentes no conteúdo dos artigos. Sabemos que essa estratégia de consulta a imagens virtuais é passível de erros, e que, politicamente, faz sentido que a classificação seja por auto-declaração, porque envolve não só aspectos estéticos, mas também identitários. 